 Species
}

\section{Renovated Breeding Habitat Use in Wild \& Captive-bred Populations of an Endangered Desert Pupfish}

\author{
Layla Al-Shaer*, Andrew Bloch, Timothy Paciorek, Zachary Carroll, Andrew Black and Murray Itzkowitz
}

Department of Biological Sciences, Lehigh University, Bethlehem, PA, USA

\begin{abstract}
The Leon Springs pupfish (Cyprinodon bovinus) is an endangered fish endemic to Diamond Y Spring in west Texas. To mitigate the negative effects of habitat loss, Diamond $Y$ Spring was renovated to maintain and provide additional breeding habitat. Monsanto Pool, an extant location where $C$. bovinus have become extirpated, was also renovated in order to increase breeding habitat. After Monsanto Pool was renovated, captive-bred $C$. bovinus were reintroduced to this location to both increase the range of this species, and evaluate whether captive release is a viable option. These conservation efforts have led to the unique opportunity to evaluate the efficacy of habitat renovations in wild and captivebred populations of $C$. bovinus, occurring in natural and renovated breeding habitats at two separate locations. The overarching question asked was, is it better to renovate an unoccupied site and introduce captive-bred individuals, or to expand an occupied site that would allow the current population to grow? Habitat use and spawning in three different breeding areas were compared, and specific ecological factors were measured at each site in order to determine if any coincided with observed $C$. bovinus location preferences. Wild $C$. bovinus in the natural breeding habitat spawned more, had more spawns per individual male, and had greater territorial stability than wild or captive-bred C. bovinus in renovated habitats. Differences in social system stability and reproductive success between sites may be due to variation in their ability to adapt to a renovated site as well as the ecological makeup of the habitat.
\end{abstract}

Keywords: Cyprinodon bovinus; Conservation; Reintroduced species; Habitat loss

\section{Introduction}

Habitat loss is a persistent threat for endangered species [13], with both natural [4] and human factors [5] contributing to the devastating fragmentation of natural environments. In extreme cases, this fragmentation can result in species having little to no natural habitat remaining in which to repopulate [6]. Attempts to combat this growing phenomenon have emerged in the form of rebuilding or expanding natural habitats in order to facilitate population re-growth $[7,8]$. However, the success of such projects has been limited, and as a result, habitat restoration alone is considered an unreliable method of mitigating species loss. This is largely due to restoration attempts facing a myriad of constraints that can impact both short and longterm progress [9], and a large proportion of restoration projects being deemed insufficient in terms of increasing population size [10].

Due in part to increased habitat loss, endangered species are often brought into captivity in order to establish assurance colonies $[11,12]$. This in turn has facilitated the reintroduction of some captive-bred endangered species back into both their former range $[1,7,12]$, and areas outside of their range with similar ecological properties [1315]. As is the case with habitat restoration, releasing individuals back into the wild is not a straightforward process, as a multitude of factors including food acquisition, predator avoidance, and acclimation to the natural habitat all must be taken into consideration for the successful establishment and persistence of a reintroduced population [1]. The successful reintroduction of species is rare across taxa [16], and additional work is needed in order to monitor those that have been released [13], as well as develop new strategies to ensure maximum species survival upon reintroduction. However, some reintroduction efforts, including populations of threatened and endangered fishes, have shown signs of success through their stable population growth $[14,15]$.

The endangered Leon Springs pupfish (Cyprinodon bovinus) represents one such conservation dilemma, with regard to habitat loss and subsequent population decline, as they are geographically restricted to a single desert spring (Diamond Y Spring) within the Diamond Y Draw in west Texas [17]. Furthermore, the conservation of $C$. bovinus presents a unique predicament, as they occur with the Pecos gambusia (Gambusia nobilis), a live-bearing Poeciliid that is not only endangered, but also an egg predator of C. bovinus $[8,18]$. This negative interspecific interaction is believed to be exacerbated by the loss of breeding habitat [8]. Habitat loss is a persistent threat and is primarily attributed to the encroachment of bulrush vegetation (Scirpus americanus), which restricts the amount of shallow, open-water areas [17]. Shallow habitats, in particular, are essential to the breeding of C. bovinus [19]. In one especially shallow area of Diamond Y Spring, there is a submerged shelf made of a compact matrix of roots and debris (herein called the natural shelf) where male C. bovinus defend breeding territories and spawn with receptive females [18,19]. As a result, the loss of the natural breeding habitat is believed to be partially responsible for the historical population decline [18].

To mitigate habitat loss in this system, and in turn help increase the natural population size, several renovations of Diamond $Y$ Spring have occurred in order to provide C. bovinus with additional shallow breeding area. These restoration efforts involved the removal and prevention of $S$. americanus regrowth in choked-up areas of the spring, which provided additional semi-natural habitat for C. bovinus

*Corresponding author: Layla Al-Shaer, Department of Biological Sciences, Lehigh University, 111 Research Drive, Bethlehem, PA, USA, Tel: 6107583680; E-mail: Lta312@lehigh.edu

Received December 10, 2015; Accepted January 04, 2016; Published January 11, 2016

Citation: Al-Shaer L, Bloch A, Paciorek T, Carroll Z, Black A, et al. (2016) Renovated Breeding Habitat Use in Wild \& Captive-bred Populations of an Endangered Desert Pupfish. J Biodivers Endanger Species 4: 156. doi:10.4172/2332-2543.1000156

Copyright: (c) $2016 \mathrm{Al}$-Shaer L, et al. This is an open-access article distributed under the terms of the Creative Commons Attribution License, which permits unrestricted use, distribution, and reproduction in any medium, provided the original author and source are credited. 
to form breeding territories and spawn $[8,20,21]$, and should reduce interspecific pressure of G. nobilis egg predation [8].

To attempt to restore the former range of C. bovinus, captive stock were reintroduced into a discrete extant location $4 \mathrm{~km}$ downstream from Diamond Y Spring, referred to as Monsanto Pool [21]. Although this area once maintained a natural population of C. bovinus, they have not been observed at this location for several years (M. Itzkowitz pers. obs.). Similar to Diamond Y Spring, Monsanto Pool is also threatened by $S$. americanus encroachment and contains a population of $G$. nobilis. The emergence of $S$. americanus into the shallow breeding habitat of C. bovinus is suspected to be related to the extirpation of C. bovinus at Monsanto Pool [22], and for this reason additional breeding pools were also created at this location prior to C. bovinus reintroduction.

Despite efforts to improve and expand the natural habitat for this species, little is known about the efficacy of this renovation process. It is important to evaluate how C. bovinus utilizes natural and renovated breeding habitats, particularly for the establishment of their social system and for reproduction. Furthermore, it is imperative that the use of renovated natural habitat by captive-bred C. bovinus be assessed in order to determine whether reintroduction efforts are an effective conservation procedure in this system. By releasing captiveraised individuals under an experimental framework, such as habitat restoration, their behaviors and ecological interactions could be used as indicators of success or failure of the restoration attempts [23], which will provide useful information for future conservation efforts.
If reintroduced C. bovinus are capable of adapting to their newly renovated natural habitat, then such reintroductions may serve to help repopulate and restore their range over time $[20,21]$.

The goal of this study was to compare natural and constructed breeding habitats, used by wild and captive-bred populations of $C$. bovinus, in order to determine how to approach future conservation efforts with regard to habitat expansion and species reintroduction. Male and female C. bovinus were observed at three locations within the Diamond Y Draw (Figure 1a), the natural shelf in Diamond Y Spring (herein referred to as $\mathrm{DY}_{\mathrm{NAT}}$ ), a constructed pool at Diamond Y Spring (herein referred to as $\mathrm{DY}_{\mathrm{CON}}^{\mathrm{NAT}}$ ), and a constructed pool at Monsanto Pool (herein referred to as $\mathrm{MP}_{\mathrm{CON}}$ ). First, the mean number of C. bovinus and spawns observed were compared between the three locations. It was hypothesized that the number of $C$. bovinus and spawns observed would vary between all sites, and that the greatest number of territorial males and spawns would be observed at $\mathrm{DY}_{\mathrm{NAT}}$. Second, how $C$. bovinus used each breeding habitat was determined by monitoring the amount of breeding habitat area used, and by observing if there were preferred areas within each site by examining the consistency of spawning and C. bovinus locations over the course of the experiment. It was hypothesized that $C$. bovinus at the natural and constructed sites would vary in their habitat use and location preference. It was predicted that territorial males would utilize the least area and show the greatest consistency in their locations compared to females and non-territorial males, and that spawns would occur throughout the breeding habitat. Additionally, it was predicted that the locations of both territorial
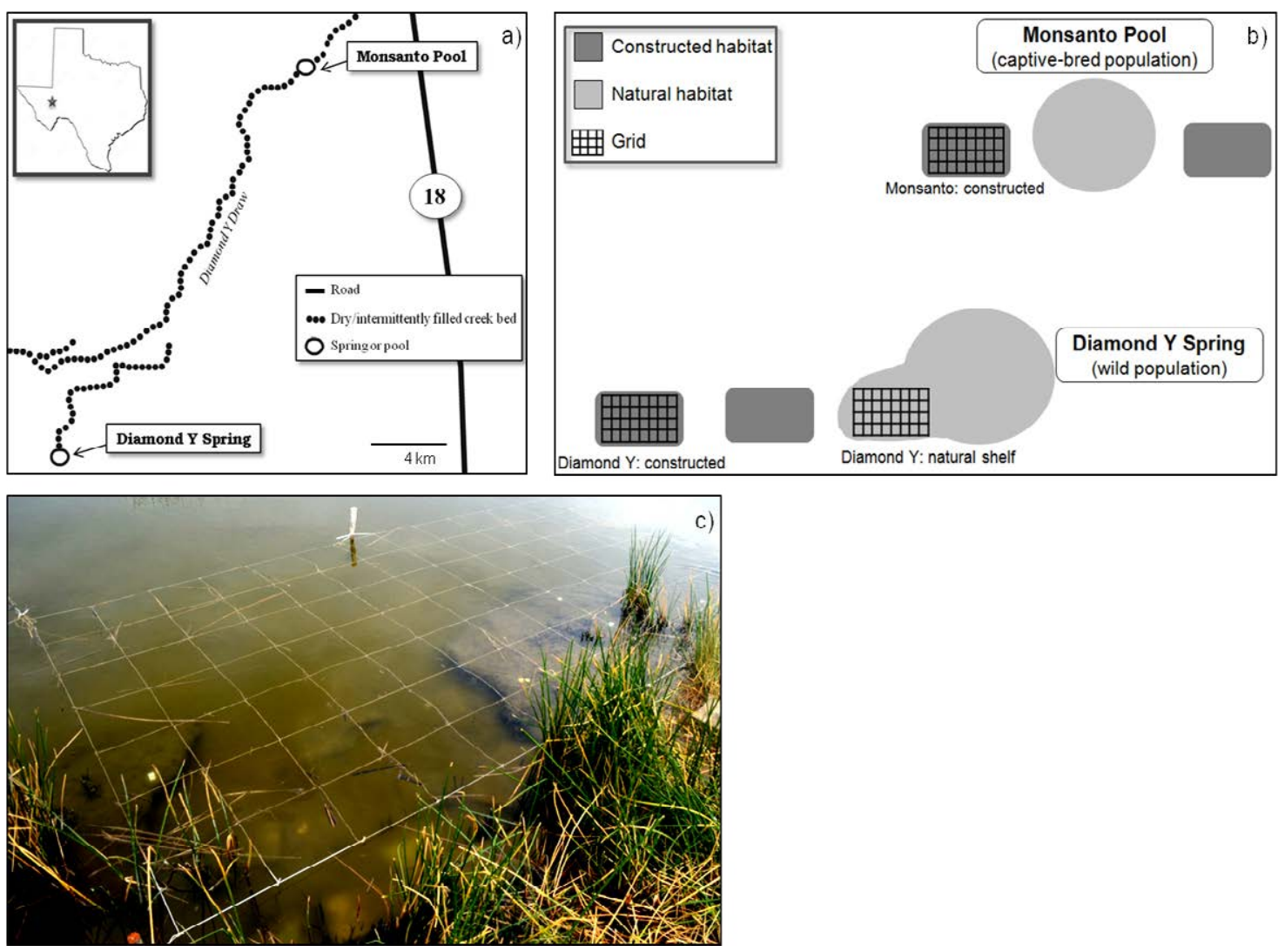

Figure 1: a. Location of the two separate habitats containing natural (Diamond Y Spring) and captive-bred (Monsanto pool) C. bovinus outside of Fort Stockton, Texas b. Diagram of the three grid locations. Two grids were installed at Diamond $Y$ Spring, one over the natural breeding area (DY $\left.{ }_{\mathrm{NAT}}\right)$, and the other over a constructed breeding pool $\left(\mathrm{DY}_{\mathrm{CON}}\right)$. The third grid was installed at Monsanto pool over a constructed breeding pool (MP $\left.\mathrm{MON}_{\mathrm{CN}}\right)$. c. Grid over the natural shelf breeding area at Diamond Y Spring. 
males and spawns would be most consistent at $\mathrm{DY}_{\mathrm{NAT}}$ versus either constructed site. Third, whether or not specific ecological factors contribute to the location preferences of $C$. bovinus was investigated by site. It was hypothesized that ecological characteristics would impact territory establishment and spawning location, but should have little effect on female or non-territorial male breeding habitat use, and that the effects of ecological factors on location preference would differ between the natural and constructed sites. Finally, a goal of this study was to understand if habitat expansions have played an effective role in conserving C. bovinus. Based on the findings, this study aimed to address a more abstract, overarching question; is it more beneficial to expand an existing breeding habitat for C. bovinus (Diamond Y Spring) in order to allow the natural population to increase, or to renovate a previously unoccupied site (Monsanto Pool) and reintroduce captive stock back into the wild in order to expand the range of this species? By understanding how both natural and constructed breeding habitats are utilized, more accurate decisions regarding future renovations in this system can be made.

\section{Methods}

\section{Species overview}

Reproduction in C. bovinus is promiscuous, with the breeding season lasting from April to October with a peak in spawning activity in July [19]. During the breeding season large males will establish and defend territories in shallow areas, often with compact substrate $[24,25]$. If a female decides to spawn with a male, she will lower to the substrate, the male will sidle up next to her, and they will form a characteristic S-shape with their bodies while the female lays one to several demersal eggs for the male to fertilize $[26,27]$. Small male $C$. bovinus, that are unable to maintain territories, are known to engage in alternative mating strategies (i.e. satellite and sneaker) where they attempt to mate irrespective of location $[28,29]$. Satellite males usually remain on the periphery of territories, and phenotypically resemble territorial males which are identified by a blue nuptial coloration and a sexually dimorphic black band at the terminus of their caudal fin $[27,30]$. Sneaker males are more likely to go unnoticed within another male's territory because they are less conspicuous due to their resemblance to females, which are drabber in color and have discontinuous lateral bars $[30,31]$

\section{Study sites}

This study was performed at two separate locations within the Diamond Y Draw, a flood tributary of the Pecos River Basin just outside of Fort Stockton, TX (Figure 1b). The first site, Diamond Y Spring $\left(31.001228^{\circ} \mathrm{N}, 102.92414^{\circ} \mathrm{W}\right)$, is fed by an underground spring that flows to the surface forming a circular headwater pool (14 $\times 25 \times 3.5 \mathrm{~m}^{3}$ ) [32]. This pool is primarily composed of a flocculent silt substrate with compact root outcrops along most of the perimeter that form submerged shelves, with the largest being the natural shelf $\left(\sim 8 \mathrm{~m}^{2}\right)$. The second study site, historically referred to as Monsanto Pool $\left(31.030615^{\circ} \mathrm{N}, 102.897897^{\circ} \mathrm{W}\right)$, is located approximately $4 \mathrm{~km}$ NE of Diamond Y Spring and consists of a refugium $\left(\sim 1 \mathrm{~m}^{2}\right)$ that overflows into surrounding shallow areas. Monsanto Pool is primarily characterized as having mostly flocculent silt substrate and very little compact substrate. Unlike Diamond Y Spring, there is no shelf present at this site.

\section{Habitat renovation}

In January of 2007, the natural shelf in Diamond Y Spring was renovated due to encroaching $S$. americanus [8]. Subsequently, in January of 2013, both Diamond Y Spring and Monsanto Pool underwent major habitat renovations that established two additional shallow breeding pools at both sites $(7 \times 2 \times .2 \mathrm{~m}$ each $)[20,21]$. The two artificial pools at Diamond Y Spring were constructed in a channel that was overrun with $S$. americanus, just downstream $(8 \mathrm{~m}$ and $16 \mathrm{~m}$ respectively) from the natural shelf of Diamond Y Spring. At Monsanto Pool, the constructed pools were placed on either side of the existing refugia. Artificial pools were constructed by manually excavating $S$. americanus, and its underlying root system, so that the pools would fill with water. All pools were connected to the existing aquatic habitat by clearing waterways that allowed the fish to move freely between the original and constructed areas. Cement tiles $(30 \times 20 \times 7.5 \mathrm{~cm})$ were then laid to prevent future regrowth. Some cement tiles remained visible while others sunk into the substrate.

\section{Species reintroduction}

In May of 2013, four hundred captive-bred C. bovinus were obtained from the Southwestern Native Aquatic Resources \& Recovery Center (SNARRC), a federal facility that maintains threatened aquatic species, and reintroduced into the newly renovated Monsanto Pool [20].

\section{Study design}

All three study locations were superimposed with string grids in order to score the locations of individual C. bovinus, spawning events and to characterize the underlying habitat ecology $[33,34]$. Each grid contained seven rows and thirteen columns, forming $91\left(30 \mathrm{~cm}^{2}\right)$ boxes which were identified by their specific $\mathrm{x}, \mathrm{y}$ coordinate on the grid. Grids were installed by tying each corner to a wooden stake, suspending the grid above the surface of the water, and were arranged so that the longest side was parallel to the shore (Figure $1 \mathrm{~b}$ and 1c).

Prior to data collection, all grid boxes were characterized based on depth, presence of vegetation, and substrate composition (Supplementary Figure 1). Mean depth of each grid box was calculated from three depth measurements, and boxes were assigned to one of four $10 \mathrm{~cm}$ depth range categories (ranging from $0-40 \mathrm{~cm}$ ). Vegetation was measured as either the presence or absence of any type of plant material growing within a grid box. Finally, each grid box was assigned to one of the following substrate categories: compact, cement, flocculent, or mixed. In order for a grid box to be considered as only one type, the substrate had to cover at least $75 \%$ of the box area. Boxes were classified as being compact if they contained hard, naturally occurring, substrate (such as the compact root substrate of the natural shelf). Cement substrate refers to the presence of cement tiles that were placed during habitat renovations. Flocculent was defined as being a loose, fine, sediment, that when settled, created the illusion of a false bottom but was not firm to the touch. When a single substrate did not cover at least $75 \%$ of the box area, the grid box was classified as mixed.

\section{Data collection}

During the peak of the 2013 breeding season (mid June-July), each grid was observed once per day for 12 non-consecutive days. Each grid was visually divided into four sections (three 3 column wide sections, and one 4 column wide section) and one observer was randomly assigned to collect data from each section. This was done so that data from the entire grid could be collected simultaneously without risking that any areas go momentarily unwatched. Data was collected from each site daily (between the hours of 12:30-17:30), for a period of 20 min not including a 2 min acclimation period. During this time, each observer recorded the grid box locations of all spawns, as well as the 
grid box locations of all territorial males, non-territorial males, and females within the grid every two minutes for a total of ten time point observations per replicate. In cases where a fish's sex or male tactic could not be visually determined, the individual was not recorded.

The daily mean number of spawns at each site was determined by averaging the total number of spawns recorded at a grid each day across the twelve days of data collection. The mean number of individuals present at a site was determined by first averaging the total number of territorial males, non-territorial males, and females that were recorded during each of the ten daily time points, and then averaging these daily means across the twelve days of data collection. In order to calculate the mean number of spawns per male at each grid location, the mean number of spawns was divided by the mean number of males (territorial and non-territorial). The amount of habitat area used for spawning at each site was determined by totaling the daily number of grid boxes where a spawning event occurred, and then averaging these daily totals across the twelve days of data collection. The amount of habitat area used per individual territorial male, non-territorial male, and female were each calculated by averaging the total number of boxes where each was observed across the ten 2 min time points, and then averaging the mean number of boxes used each day across the twelve days of data collection and dividing by the mean number of individuals present. Consistency in grid box location preference in males, females, and for spawning at each grid site, were each calculated by finding the total number of days, out of twelve, that a grid box was reused. Location consistency was only determined for boxes where a fish or spawning event was observed at least once. The effect of substrate type, depth, and presence of vegetation on the number of days each box was reused was also examined. Since the ecological factors measured were not significant when it came to non-territorial male and female location consistency across sites (Supplementary Table 1), they were excluded from further analyses. Within site differences between the ecological factors measured and grid box location consistency were further explored for territorial males and spawns.

\section{Statistical analyses}

Differences between grid sites in the mean number of territorial males, non-territorial males, females, spawns, and spawns per male were each analyzed using a one-way ANOVA. A one-way ANOVA was also used to analyze between site differences in mean amount of habitat area occupied per individual and mean number of days a box was reused for territorial males, non-territorial males, females and spawns. Three-way ANOVAs were used to look for all possible effects of substrate type, depth, and presence of vegetation on the number of days boxes were reused for spawns, territorial males, non-territorial males, and females across all sites. The effects of substrate type, presence of vegetation, and depth, on territorial male and spawning location consistency, were each analyzed by grid site using a one-way ANOVA. An adjusted Welch F-statistic is reported for all tests that violated the assumption of homogeneity of variance. All significant ANOVA results were further analyzed by conducting pairwise comparisons using either Tukey HSD, Games-Howell, or Bonferroni post hoc tests. The post hoc test used depended on if the data met all assumptions, violated homogeneity of variance only, or if there were unequal sample sizes and/or unequal variance respectively. All data were found to be normally distributed and were analyzed using IBM SPSS Statistics Version 21.

\section{Results}

\section{Comparison of grid population size and spawning frequency between sites}

The mean number of territorial male, non-territorial male, and female C. bovinus observed differed between grid locations; means $\pm \mathrm{SE}$ can be found in Table 1 . The number of territorial males observed was unequal between sites $\left(F_{2,17.21}=212.05, p<0.001\right)$, with fewer territorial

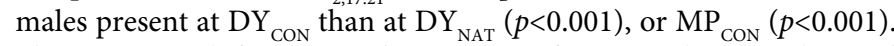
There was no difference in the number of territorial males observed at $\mathrm{DY}_{\mathrm{NAT}}$ and $\mathrm{MP}_{\mathrm{CON}}(p=0.958)$. The number of non-territorial males varied between sites $\left(F_{2,20.35}=3.73, p=0.042\right)$, with more present at $\mathrm{MP}_{\mathrm{CON}}$ than at $\mathrm{DY}_{\mathrm{CON}}(p=0.038)$, but not $\mathrm{DY}_{\mathrm{NAT}}(p=0.054)$. The two grids in Diamond $Y$ Spring did not differ in the amount of non-territorial males observed $(p=0.895)$. Females also differed between sites $\left(F_{2,18.18}=11.56\right.$, $p=0.001)$; there were more females observed at $\mathrm{MP}_{\mathrm{CON}}$ than at $\mathrm{DY}_{\mathrm{NAT}}$ $(p=0.002)$, or $\mathrm{DY}_{\mathrm{CON}}(p=0.007)$. The number of females observed did not differ between the two Diamond Y Spring grid locations $(p=0.086)$.

The number of spawns occurring at each grid site were not equal (means \pm SE in Table $1, F_{2,33}=18.44, p<0.001$ ), with significantly more spawns at $\mathrm{DY}_{\mathrm{NAT}}$ than at $\mathrm{DY}_{\mathrm{CON}}(p<0.001)$, or $\mathrm{MP}_{\mathrm{CON}}(p=0.002)$. The two constructed sites did not differ in the amount of spawns observed $(p=0.062)$. The number of spawns per male varied between grid locations (Figure 2, $F_{2,19.34}=5.10, p=0.017$ ), with males at DY $\mathrm{NAT}$ spawning more per individual (mean $=2.07, S E \pm 0.29$ ) than those at $\mathrm{MP}_{\mathrm{CON}}($ mean $=0.97, S E \pm 0.18, p=0.012)$, but not $\mathrm{DY}_{\mathrm{CON}}$ (mean=1.13, $S E \pm 0.49, p=0.246)$. The number of spawns per male did not differ between the two constructed sites (mean difference $=0.16, S E \pm 0.52$, $p=0.949$ ).

\begin{tabular}{|c|c|c|c|c|c|c|}
\hline & DY $_{\text {NAT }}$ & DY $_{\text {coN }}$ & MP $_{\text {CON }}$ \\
\hline Territorial males & $10.8 \pm 0.4$ & $\mathrm{a}$ & $1.4 \pm 0.2$ & $\mathrm{~b}$ & $10.5 \pm 1.0$ & $\mathrm{a}$ \\
\hline Non-territorial males & $1.6 \pm 0.2$ & $\mathrm{a}$ & $1.5 \pm 0.3$ & $\mathrm{a}$ & $2.9 \pm 0.4$ & $\mathrm{~b}$ \\
\hline Females & $2.4 \pm 0.3$ & $\mathrm{a}$ & $3.7 \pm 0.5$ & $\mathrm{a}$ & $11.8 \pm 2.1$ & $\mathrm{~b}$ \\
\hline Spawns & $25.2 \pm 3.3$ & $\mathrm{a}$ & $3.8 \pm 1.8$ & $\mathrm{~b}$ & $12.2 \pm 2.2$ & $\mathrm{~b}$ \\
\hline
\end{tabular}

Table shows daily means \pm SE. Different letters across a row indicate significant differences between locations.

Table 1: Daily mean number of $C$. bovinus and spawns observed at each grid location.

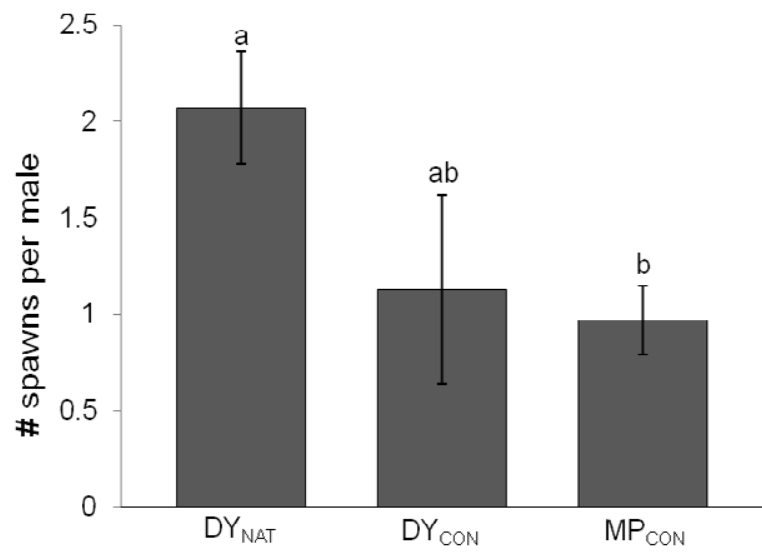

Figure 2: Daily mean number of spawns per male at each site $\pm S E$. Males at $\mathrm{DY}_{\mathrm{NAT}}$ spawned more each day than those at $\mathrm{MP}_{\mathrm{CON}}$ (ANOVA, $p=0.012$ ), but not DY ${ }_{\text {CON. }}$. There was no difference between the two constructed sites. Bars that do not share letters are significantly different from one another $(n=12$ for each site). 
To summarize, the location with the most fish present overall was $\mathrm{MP}_{\mathrm{CON}}$, and the location with the least fish and spawns was $\mathrm{DY}_{\mathrm{CON}}$. The most spawns occurred at $\mathrm{DY}_{\mathrm{NAT}}$. Spawns per male were greater at $\mathrm{DY}_{\mathrm{NAT}}$ than at $\mathrm{MP}_{\mathrm{CON}}$.

\section{Differences in habitat area used and location consistency}

Territorial males at each site varied in the number of grid boxes occupied per individual (Figure $3 \mathrm{a}, F_{2,18.95}=52.21, p<0.001$ ), with those in $\mathrm{DY}_{\mathrm{NAT}}$ using fewer boxes (mean=2.54, $S E \pm 0.11$ ) than those at either constructed site $\left(\mathrm{DY}_{\mathrm{CON}}\right.$ mean $=6.32, S E \pm 0.38, p<0.001 ; \mathrm{MP}_{\mathrm{CON}}$ mean $=3.74, S E \pm 0.19, p<0.001)$. Individual territorial males in $\mathrm{DY}_{\mathrm{CON}}$ utilized more boxes than those at $\mathrm{MP}_{\mathrm{CON}}$ (mean difference $=2.58, S E$ $\pm 0.42, p<0.001)$. Females also varied between sites in the amount of habitat area used (Figure $3 b, F_{2,33}=21.01, p<0.001$ ), with females at $\mathrm{DY}_{\mathrm{NAT}}$ utilizing more grid boxes per individual (mean=8.21, $S E \pm$ $0.28)$ than those at $\mathrm{DY}_{\mathrm{CON}}($ mean $=5.34, S E \pm 0.67, p=0.003)$, or $\mathrm{MP}_{\mathrm{CON}}$ (mean $=3.05, S E \pm 0.66, p<0.001$ ). Females at $\mathrm{DY}_{\mathrm{CON}}$ used more grid area than those at $\mathrm{MP}_{\mathrm{CON}}$ (mean difference $=2.29, S E \pm 0.80, p=0.019$ ). Nonterritorial males did not differ in the number of grid boxes used per individual between sites (Figure $3 c, F_{2,33}=2.50, p=0.097$ ). The number of grid boxes where spawns occurred differed between the three sites (Figure 4, F2,33=52.21, $p<0.001$ ). Significantly more boxes were used for spawning at $\mathrm{DY}_{\mathrm{NAT}}$ (mean=12.5, $S E \pm 1.42$ ) than at either of the constructed breeding sites ( $\mathrm{DY}_{\mathrm{CON}}$ mean $=2.75, S E \pm 1.24, p<0.001$; $\mathrm{MP}_{\mathrm{CON}}$ mean $\left.=7.9, S E \pm 1.27, p=0.048\right)$, and more grid boxes were used for spawning at $\mathrm{MP}_{\mathrm{CON}}$ than at $\mathrm{DY}_{\mathrm{CON}}$ (mean difference $=5.17, S E \pm 1.86$, $p=0.023)$.

Territorial males varied between sites in the number of days they were observed reusing grid boxes (Figure $5 \mathrm{a}, F_{2,101.86}=59.87$, $p<0.001)$. Territorial males in $\mathrm{DY}_{\mathrm{NAT}}$ were observed reusing grid boxes for a greater number of days (mean $=6.46, S E \pm 0.61)$ than those at $\mathrm{DY}_{\mathrm{CON}}($ mean $=2.19, S E \pm 0.22, p<0.001)$, but not those at $\mathrm{MP}_{\mathrm{CON}}$ (mean=5.70, $S E \pm 0.28, p=0.465)$. Territorial males in $\mathrm{MP}_{\mathrm{CON}}$ showed

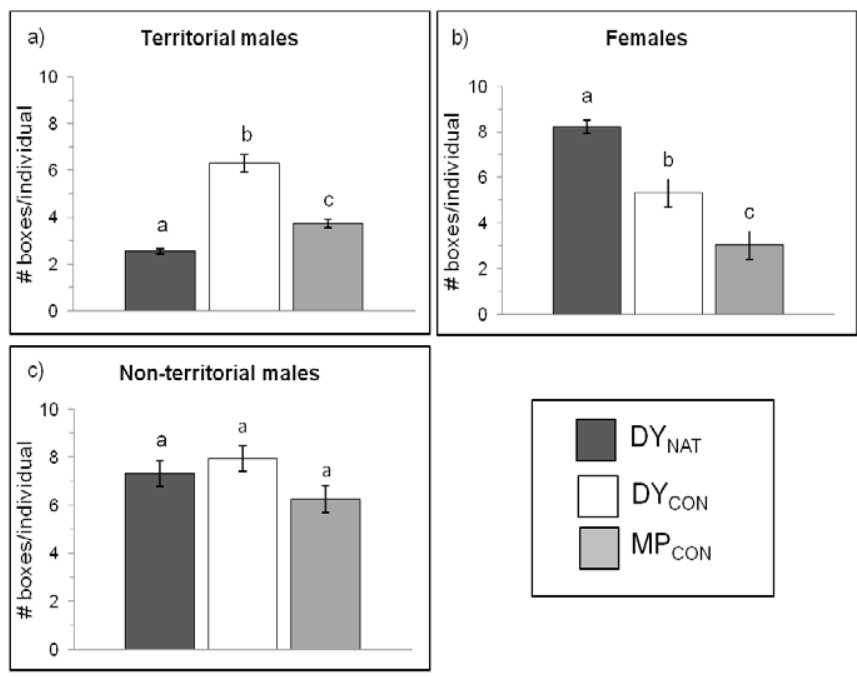

Figure 3: Daily mean number of boxes used per individual $\pm S E$. a. Number of boxes used per individual territorial male differed between all grid locations (ANOVA, $p<0.001$ ), with those at $D Y_{N A T}$ dispersing the least. b. Females differed in the number of boxes used per individual (ANOVA, $p<0.001$ ), with those at DY There was no difference in the number of boxes used per non-territorial male between sites (ANOVA, $p=0.097$ ). Bars that do not share the same letters are significantly different from one another ( $n=12$ for each site).

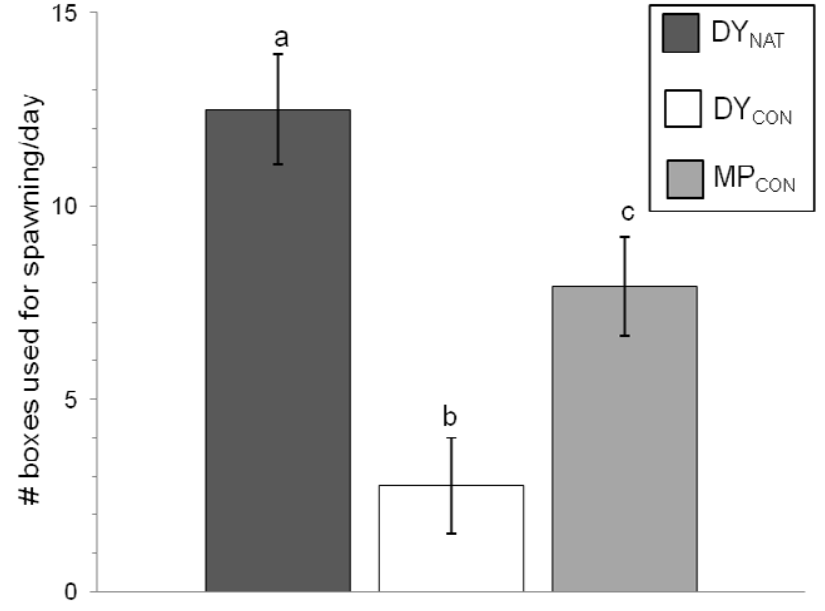

Figure 4: Daily mean number of boxes used at least once for spawning $\pm S E$. All sites varied in the amount of grid area that was used for spawning (ANOVA, $p<0.001)$. More of the grid area was utilized for spawning at DY ${ }_{\text {NAT }}$ than at either of the constructed sites. Bars that do not share letters are significantly different from one another ( $n=12$ for each site).
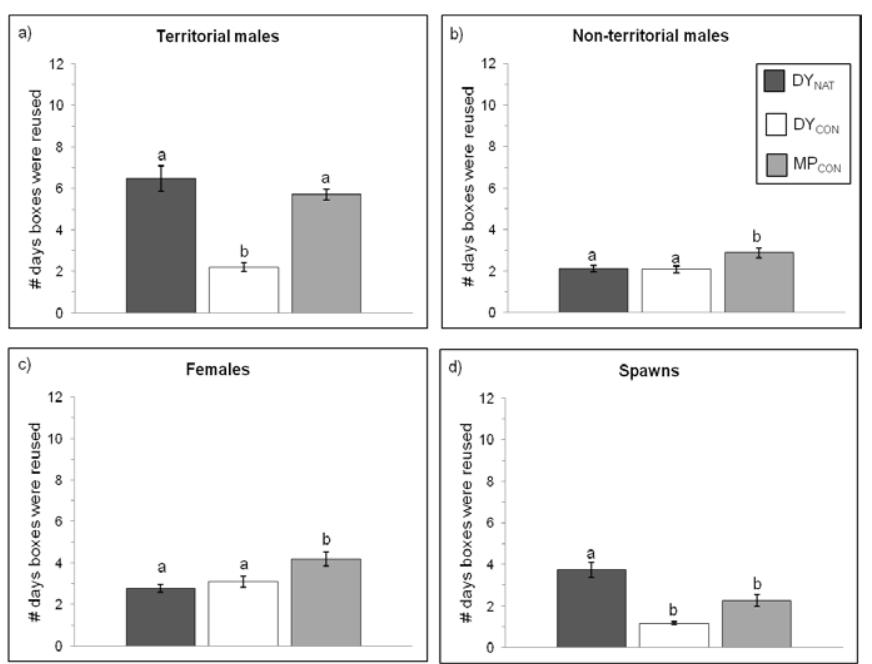

Figure 5: Mean number of days boxes were reused (consistency) \pm SE.a. Territorial male locations were less consistent at $D Y_{C O N}$ than at the other two sites (ANOVA, $p<0.001$ ). b. Non-territorial males at $\mathrm{MP}_{\mathrm{CON}}$ were more consistent than those at either Diamond $Y$ Spring site (ANOVA, $p=0.013$ ). c. Females at $\mathrm{MP}_{\text {oO }}$ were more consistent in their location preference than those at the two Diamond $Y$ Spring sites (ANOVA, $p=0.002$ ). d. Spawning location was more consistent at $D Y_{N A T}$ than at either of the constructed breeding pools (ANOVA, $p<0.001$ ). Only boxes that were used at least once were included, and were scored as 'used' or 'unused' each day regardless of if there were repeat visits during an observation period. Bars that do not share letters are significantly different from one another.

greater consistency in their grid box reuse than those in $\mathrm{DY}_{\mathrm{CON}}$ (mean difference $=3.51, S E \pm 0.55, p<0.001)$. Non-territorial males varied in the number of days they reused grid boxes (Figure $5 \mathrm{~b}, F_{2,128.00} 4.49$, $p=0.013$ ), with those in $\mathrm{MP}_{\mathrm{CON}}$ having greater box reuse over the course of the experiment (mean $=2.87, S E \pm 0.23$ ) than those at DY (mean=2.11, $S E \pm 0.18, p=0.017$ ), or $\mathrm{DY}_{\mathrm{CON}}$ (mean=2.08, $S E \pm 0.16$, $p=0.013)$. Non-territorial males at the two Diamond Y Spring locations did not differ in the number of days they were observed reusing grid boxes (mean difference $=0.03, S E \pm 0.24, p=0.991$ ). Females also 
varied in their location consistency (Figure $5 c, F_{2,128.95}=6.75, p=0.002$ ), with those at $\mathrm{MP}_{\mathrm{CON}}$ reusing grid boxes for a greater number of days (mean=4.19, $S E \pm 0.34$ ) than those at $\mathrm{DY}_{\mathrm{NAT}}$ (mean=2.77, $S E \pm 0.18$,

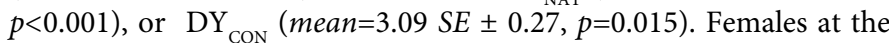
two Diamond Y Spring grid sites did not differ in their box reuse consistency (mean difference $=-0.32, S E \pm 0.38, p=1.000$ ). The number of days a box was used for spawning also varied between sites (Figure $\left.5 \mathrm{~d}, F_{2,59.03}=28.09, p<0.001\right)$. Cyprinodon bovinus in $\mathrm{DY}_{\mathrm{NAT}}$ were more consistent in their reuse of boxes for spawning (mean $=3.73, S E \pm 0.37$ ) than those at either renovated grid site (DY ${ }_{\mathrm{CON}}$ mean $=1.18, S E \pm 0.07$, $p<0.001 ; \mathrm{MP}_{\mathrm{CON}}$ mean $\left.=2.26, S E \pm 0.29, p=0.001\right)$. The two constructed sites showed no difference in the number of days boxes were reused for spawning (mean difference $=-1.08, S E \pm 0.45, p=0.056$ ).

To summarize, territorial males at $\mathrm{DY}_{\mathrm{NAT}}$ occupied the least boxes per individual and had greater consistency in their box reuse than those at $\mathrm{DY}_{\mathrm{CON}}$. Females utilized the most grid boxes in $\mathrm{DY}_{\mathrm{NAT}}$, but females and non-territorial males were the most consistent in their box reuse at $\mathrm{MP}_{\mathrm{CON}} \cdot \mathrm{DY}_{\mathrm{NAT}}$ had the most area that was used for spawning and the highest consistency in boxes reused for spawning.

\section{Ecological factors and habitat use}

At DY ${ }_{\mathrm{NAT}}$, the number of days a grid box was reused as a spawning location differed by substrate type (Figure $6 \mathrm{a}, F_{3,37=} 4.56, p=0.008$ ), with grid boxes containing compact substrate (mean=4.77, $S E \pm 0.50$ ) being reused more than those with flocculent substrate (mean=1.86, $S E \pm$ $0.55, p<0.017)$. Substrate type had no effect on the number of days a grid box was reused for spawning at either constructed site (Figure $6 \mathrm{~b}, \mathrm{DY} \mathrm{CON}_{2,25} 1.44, p=0.257$; Figure $\left.6 \mathrm{c}, \mathrm{MP}_{\mathrm{CON}}, F_{3,10.54=} 1.88, p=0.194\right)$. At $\mathrm{MP}_{\mathrm{CON}}$, boxes containing vegetation (mean $=2.44, S E \pm 0.33$ ) were reused more for spawning than those without (mean $=1.17, S E \pm 0.17$; $\left.F_{1,37.74=} 12.11, p=0.001\right)$. There was no effect of vegetation on the number of days a grid box was reused for spawning at $\mathrm{DY}_{\mathrm{NAT}}\left(F_{1,39=} 0.062\right.$, $p=0.805)$, or DY ${ }_{\mathrm{CON}}\left(F_{1,26=} 0.21, p=0.650\right)$. The number of days a box was reused for spawning differed by depth category at $\mathrm{MP}_{\mathrm{CON}}\left(F_{1,40} 5.74\right.$, $p=0.021$ ), with boxes $10-20 \mathrm{~cm}$ deep (mean $=3.36, S E \pm 0.62$ ) being reused more than boxes $<10 \mathrm{~cm}$ deep (mean $=1.87, S E \pm 0.30$ ). There was no effect of depth category on spawning location box consistency at $\mathrm{DY}_{\mathrm{NAT}}\left(F_{3,37=} 2.33, p=0.090\right)$, or $\mathrm{DY}_{\mathrm{CON}}\left(F_{2,25=} 0.25, p=0.780\right)$. At DY ${ }_{\mathrm{NAT}}$, the number of days territorial males were observed in a grid box varied based on the substrate type present (Figure $6 \mathrm{~d}, F_{3,48} 19.96, p<0.001$ ). Territorial males were observed reusing boxes with flocculent substrate (mean=2.25, SE \pm 0.52) for fewer days than those with compact (mean=9.86, $S E \pm 0.67, p<0.001$ ) or mixed substrate (mean=6.86, $S E \pm 1.30, p=0.010$ ), and boxes containing cement (mean=5.00, $S E$ \pm 1.57 ) were reused less than those with compact substrate (mean difference $=-4.86, S E \pm 1.32, p=0.004)$. The consistency of territorial male box reuse did not vary by substrate type at $\mathrm{DY}_{\mathrm{CON}}$ (Figure $6 \mathrm{e}$, $F_{244=} 0.56, p=0.575$ ), or $\mathrm{MP}_{\mathrm{CON}}$ (Figure $6 \mathrm{f}, F_{3,75=} 1.38, p=0.257$ ). The number of days territorial males reused a box was higher in those with vegetation, versus those without, at both $\mathrm{DY}_{\mathrm{NAT}}$ (Vegetation: mean $=8.21, S E \pm 0.81$; No vegetation: mean $=5.00, S E \pm 0.81 ; F_{1,50=} 7.88$, $p=0.007)$ and $\mathrm{MP}_{\mathrm{CON}}$ (Vegetation: mean $=6.25, S E \pm 0.30$; No vegetation: mean $\left.=3.83, S E \pm 0.46 ; F_{177=} 15.82, p<0.001\right)$. Depth affected territorial male box reuse at $\mathrm{DY}_{\mathrm{NAT}}\left(F_{3,21.72=} 18.50, p<0.001\right)$; boxes $30-40 \mathrm{~cm}$ deep (mean=2.09, $S E \pm 0.49$ ) were reused for fewer days than those $<10 \mathrm{~cm}$ deep (mean $=9.00, S E \pm 1.49, p=0.001)$, and 10-20 cm deep (mean=9.12, $S E \pm 0.92, p<0.001)$. Grid boxes $20-30 \mathrm{~cm}$ deep (mean $=5.38, S E \pm 0.96)$ were reused less than boxes $10-20 \mathrm{~cm}$ deep (mean difference $=-3.74$, $S E \pm 1.23, p=0.023)$. The number of days a territorial male reused a grid box also differed by depth category at $\mathrm{MP}_{\mathrm{CON}}\left(F_{1,77=} 7.99, p=0.006\right)$, with boxes 10-20 $\mathrm{cm}$ deep (mean $=7.19, S E \pm 0.41$ ) being reused more than boxes $<10 \mathrm{~cm}$ deep (mean $=5.32, S E \pm 0.32$ ). There was no effect of depth on the number of days territorial males reused boxes at $\mathrm{DY}_{\mathrm{CON}}$ $\left(F_{2,44=} 0.40, p=0.673\right)$.

To summarize, spawning and territorial male consistency in box reuse at $\mathrm{DY}{ }_{\mathrm{NAT}}$ was greatest in areas with compact substrate; but there was no evidence of substrate preference at either constructed site. $\mathrm{MP}_{\mathrm{CON}}$ was the only site where spawning box reuse varied based on the presence of vegetation and depth. Territorial male grid box reuse varied based on the presence of vegetation and depth at both $\mathrm{DY}_{\mathrm{NAT}}$ and $\mathrm{MP}_{\mathrm{CON}}$. None of the ecological factors measured had a significant effect on box reuse at $\mathrm{DY}_{\mathrm{CON}}$.

\section{Discussion}

Although it is interesting that there was a large disparity in the number of territorial males and spawns within the two Diamond $\mathrm{Y}$ Spring sites, this dichotomy is not surprising since natural habitats are expected to be preferred to altered habitats $[35,36]$. This is because habitat preferences are presumably shaped by the potential fitness

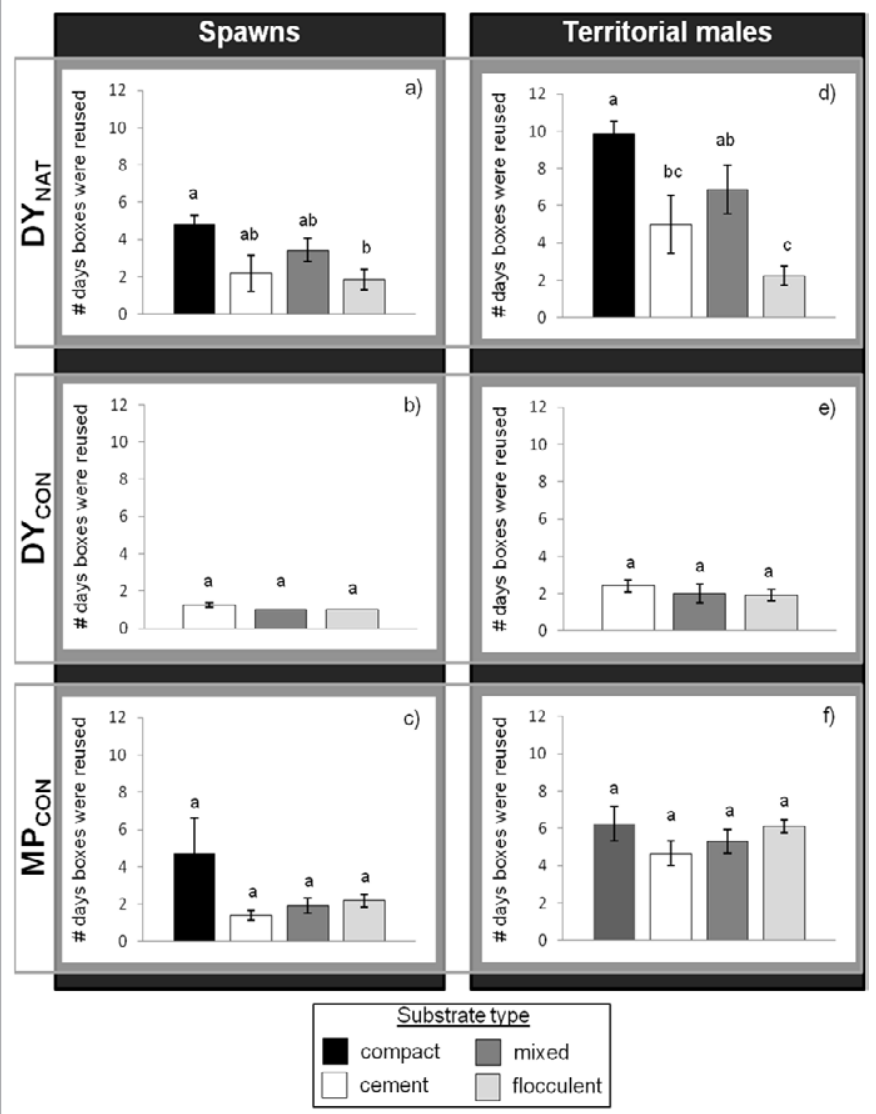

Figure 6: Mean number of days a box was reused \pm SE for spawning and by territorial males based on substrate types at each grid location. a. Spawning location consistency at DY ${ }_{\text {NAT }}$ was greater in boxes with compact versus flocculent substrate (ANOVA, $p=0.017$ ). b. Spawning consistency did not vary by substrate type at $D Y_{\mathrm{CON}}$, c. or at $\mathrm{MP}_{\mathrm{CON}}$. d. At $D Y_{\mathrm{NAT}}$, territorial male location consistency was greater in boxes containing compact substrate compared to those with cement or flocculent, but not mixed substrate; boxes with flocculent substrate were reused the least (ANOVA, $p<0.001$ ), e.Territorialmale location consistency was notaffected bysubstratetypeat $D Y_{\text {CoN }}$. f. $\mathrm{MP}_{\text {con }}$ was also not affected by substrate type. Bars that do not share letters are significantly different from one another. 
consequences of choosing an inferior habitat [37]. By favoring a familiar habitat $C$. bovinus may be demonstrating habitat preference, since organisms often show a preference for areas they perceive as valuable by revisiting and spending more time in these areas $[38,39]$.

Habitat exploration can be costly [40] in terms of energetic demands [41], missed opportunities [42], and predation risks [43], and thus, in a new or expanded habitat, organisms are forced to tradeoff between their need to explore the new habitat (e.g. for improved resources, predator avoidance or better mating opportunities) and their need to exploit resources with which they are already familiar [4446]. Additionally, recruitment to the constructed site within Diamond Y Spring may require additional time for an overflow population to be generated. Since the search costs to find the constructed habitat are presumably small, due to its close proximity to the natural shelf, it is likely that the number of inhabitants at $\mathrm{DY}_{\mathrm{CON}}$ will be able to grow over time.

In contrast to $\mathrm{DY}_{\mathrm{CON}}, \mathrm{MP}_{\mathrm{CON}}$ had a large population of C. bovinus. This was because 400 individuals had been released into Monsanto Pool two months prior. In spite of the large number of individuals released, the number of territorial males did not differ between the wild population at $\mathrm{DY}_{\mathrm{NAT}}$ and the captive-bred population at $\mathrm{MP}_{\mathrm{CON}}$. This similarity in the number of territorial males present could be an indication of the captive population's ability to establish a social system in an unfamiliar habitat [47], because Cyprinodon males compete heavily in order to secure and maintain a territory in an area where females preferentially oviposit [26], and territory establishment at $\mathrm{MP}_{\mathrm{CON}}$ indicates the captive population's readiness to reproduce. However, the number of spawns and spawns per male at $\mathrm{MP}_{\mathrm{CON}}$ were both less than half of what was observed in $\mathrm{DY}_{\mathrm{NAT}}$, suggesting that the captive population was not fully established at the time of this study.

Since territorial C. bovinus faithfully guard small portions of the breeding habitat throughout the breeding season [28], the results, showing that territorial males at $\mathrm{DY}_{\mathrm{NAT}}$ held the smallest most-stable territories, were consistent with what was expected. In contrast, territorial males at $\mathrm{DY}_{\mathrm{CON}}$ were observed in many more grid boxes, and showed little consistency in their locations, suggesting that these males were not holding true territories. Since few males were present in DY there presumably would have been little intrasexual competition, which would allow males to hold large, loose territories [29]. Unlike $\mathrm{DY}_{\mathrm{CON}}$, territorial males at $\mathrm{MP}_{\mathrm{CON}}$ resembled $\mathrm{DY}_{\mathrm{NAT}}$ in their habitat use, the only difference being that territory size was greater at $\mathrm{MP}_{\mathrm{CON}}$. This variation in territory size could be an indication of differences in intrasexual competition [29], resource quality [48], and/or familiarity with the habitat $[49,50]$.

Females and non-territorial males are not restricted to a territorial area and were therefore expected to be wide-ranging and show little location preference within the breeding habitats. Although this was true for non-territorial males, females at each site differed in the amount of habitat area they occupied and how often they revisited specific grid box locations. The most striking of these differences occurred at $\mathrm{MP}_{\mathrm{CON}}$, there females were observed in shoals that remained relatively stationary [L. Al-Shaer pers. obs.], which may explain why females at this location used little of the grid area and had the highest consistency in their grid box reuse.

As predicted, spawning occurred throughout more of the grid area, and C. bovinus showed the greatest consistency in their spawning locations at $\mathrm{DY}_{\mathrm{NAT}}$. Cyprinodon bovinus in the constructed sites did not vary in their spawning location consistency, but differed in the number of boxes used for spawning, of which $\mathrm{MP}_{\mathrm{CON}}$ used more. The amount of constructed habitat that $C$. bovinus used for spawning is an indication of how much of the renovated habitat has been readily accepted as a breeding site.

At $\mathrm{DY}_{\mathrm{NAT}}$, territorial C. bovinus defended breeding territories that were primarily clustered on the natural shelf, which is comprised of compact substrate. Areas with compact substrate were also preferentially chosen for spawning at this location. Substrate, however, had no effect on territorial male or spawning location preference at either constructed site. Given that previous research has highlighted the use of compact substrate shelves and stone ledges by Cyprinodon $s p$. for spawning $[18,19,51]$, cement tiles were incorporated into the constructed pools in an attempt to replicate their natural breeding sites, and to provide a substrate for territory establishment and reproduction. Across sites, grid boxes that contained cement were reused less than those containing compact substrate, indicating that cement is not a preferred spawning substrate (Supplementary Table 1). Since the two Diamond Y Spring sites share a common wild population, individuals at $\mathrm{DY}_{\mathrm{CON}}$ would be expected to have the same ecological preferences as those at $\mathrm{DY}_{\mathrm{NAT}}$. This could explain their reluctance to utilize $\mathrm{DY}_{\mathrm{CON}}$ which contains little compact substrate (Supplementary Figure 1). Since this data is only representative of the first breeding season postrenovations, additional observations are required to determine if cement is an adequate substitute for natural compact substrate in the long-term.

Unlike $\mathrm{DY}_{\mathrm{NAT}}$, where territorial male location consistency was the only factor to correspond with vegetation, in $\mathrm{MP}_{\mathrm{CON}}$ the presence of vegetation coincided with both spawning and territorial male box reuse. Given that all C. bovinus at $\mathrm{MP}_{\mathrm{CON}}$ were introduced from a captive facility, it is possible that their ecological preferences have shifted from those of the wild population as a result of being raised in a hatchery [49,52]. At SNARRC, C. bovinus are maintained in an outdoor cement pond covered by a plastic liner that prevents vegetation from taking root [L. Al-Shaer pers. obs.]. The contrast in habitat makeup between the hatchery pools at SNARRC and $\mathrm{MP}_{\mathrm{CON}}$ may have had an impact on the captive population's ability to immediately transition. However, in the absence of a breeding shelf, Cyprinodon sp. will establish territories around vegetation and/or other submerged structures that can be used as a spawning surface $[25,26,53-55]$. The same may be true of $C$. bovinus at $\mathrm{MP}_{\mathrm{CON}}$, which lacking a natural breeding shelf, demonstrated a preference for grid boxes with ecological features that could facilitate spawning (i.e. vegetation). Without releasing captive-bred fish into a habitat with a natural breeding shelf, or further monitoring $\mathrm{MP}_{\mathrm{CON}}$, it is impossible to know whether the observed spawning location preferences at $\mathrm{MP}_{\mathrm{CON}}$ are an artifact of being in captivity, the result of little compact substrate being present at this location, or simply because relatively little time had elapsed since the captive-bred C. bovinus were reintroduced.

Reintroductions need to be temporally monitored before evaluating the success of the release, focusing not only on the survival of the captive population, but also on how they behave in an unfamiliar habitat. For example, several studies concerned with the reintroduction of captive golden lion tamarins (Leontopithecus rosalia), have observed that captive tamarins showed a deficiency in behavior when reintroduced into their natural habitat $[1,56]$. Many refused to utilize the natural habitat due to their habituation to the conditions at captive facilities, and as such, did not develop adequate locomotor, feeding, or navigation skills in comparison to wild tamarins [1]. However, differences in behavior between both captive adult tamarins and their 
offspring decreased over time, indicating that captive-born animals are capable of acclimating to their natural habitat $[1,56]$. Therefore, it is possible that over several generations, the captive-bred population at $\mathrm{MP}_{\mathrm{CON}}$ will become more reproductively successful as they continue to acclimate their behaviors and preferences in accordance with their present environment.

Monitoring the use of constructed habitats and reintroductions of C. bovinus will improve upon current conservation methods and terminate ineffective procedures. Regardless of the initial success of the constructed habitats, in terms of the number of fish and spawns observed, any net gain in reproduction should only help to improve the population's stability. However, when the purpose of habitat renovations are aimed at increasing the range of a species, the initial success at reintroduction would be pivotal to the prosperity of the new population [57]. The dilemma of whether it is better to improve on the natural habitat of C. bovinus, or generate new habitat where captive-bred individuals can be reintroduced, is not easily decided. The initial success of a conservation plan does not determine the long term viability of the solution, and therefore, continued monitoring over several successive breeding seasons is needed to more accurately address this question.

\section{Acknowledgements}

We would like to thank the Texas Parks and Wildlife Department for funding this project through a Section 6 Grant (TX E-150-R), and The Nature Conservancy for allowing us access to the Diamond $Y$ Spring system. We would like to thank Matthew Franklin for his help in the field, and Lanshi Li, Louise McCallie, and Caroline Rago for help in the collection of this data. This project was also supported by Lehigh University's Biosystems Dynamics Summer Institute program, made possible through a grant awarded by the Howard Hughes Medical Institute.

\section{Conflict of Interest}

The authors declare that they have no conflict of interest.

\section{Compliance with Ethical Standards}

The procedures used in this study were in accordance with Texas Parks and Wildlife permit \# SPR-0812-967, and adhered to the guidelines set forth by the Animal Behaviour Society/Association for the Study of Animal Behaviour (Animal Behaviour, 2006, 71, 245-253), and met all legal requirements for animal research in the United States.

\section{References}

1. Kleiman DG, Beck BB, Dietz JM, Dietz LA, Ballou JD, et al. (1986) Conservation program for the golden lion tamarin: captive research and management, ecological studies, educational strategies, and reintroduction. In: Benirschke E (ed) Primates: the road to self-sustaining populations. Springer-Verlag, New York, pp. 959-979.

2. Hoekstra JM, Boucher TM, Ricketts TH, Roberts C (2005) Confronting a biome crisis: global disparities of habitat loss and protection. Ecol Lett 8: 23-29.

3. Cushman SA (2006) Effects of habitat loss and fragmentation on amphibians: A review and prospectus. Biol Conserv 128: 231-240.

4. Ameca y Juárez EI, Eric I, Ellis EA, Rodríguez-Luna E (2015) Quantifying the severity of hurricanes on extinction probabilities of a primate population: Insights into "Island" extirpations. Am J Primatol 77: 786-800.

5. Sanderson EW, Malanding J, Levy MA, Redford KH, Wannebo AV, et al. (2002) The human footprint and the last of the wild. BioScience 52: 891-904.

6. Kerr JT, Deguise I (2004) Habitat loss and the limits to endangered species recovery. Ecol Lett 7: 1163-1169.

7. Dietz JM, Dietz LA, Nagagata EY (1994) The effective use of a flagship species for conservation of biodiversity: the example of lion tamarins in Brazil. In: Olney PJS, Mace GM, Feistner ATC (eds) Creative conservation: interactive management of wild and captive animals. Chapman and Hall, London, pp. 32 49.

8. Gumm JM, Snekser JL, Leese JM, Little KP, Leiser JK, Imhoff VE, et al.
(2011) Management of interactions between endangered species using habita restoration. Biol Conserv 144: 2171-2176.

9. Bond NR, Lake PS (2003) Local habitat restoration in streams: Constraints on the effectiveness of restoration for stream biota. Ecol Manage Restor 4 193-198.

10. Smokorowski KE, Withers KJ, Kelso JRM (1998) Does habitat creation contribute to management goals? An evaluation of literature documenting freshwater habitat rehabilitation or enhancement projects. Can. Tech. Rep. Fish. Aquat. Sci. No. 2249.

11. Soulé ME, Gilpin M, Conway W, Foose T (1986) The millennium ark: how long a voyage, how many staterooms, how many passengers? Zoo Biol 5: 101-113.

12. Kleiman DG, Mallinson JJC (1998) Recovery and management committees for lion tamarins: partnerships in conservation planning and implementation. Conserv Biol 12: 27-38.

13. Kleiman DG (1989) Reintroduction of captive mammals for conservation BioScience 39: 152-161.

14. Mueller GA, Wydowski R (2004) Reintroduction of the flannelmouth sucker in the lower Colorado River. N Am J Fish Manage 24: 41-46.

15. Shute JR, Rakes PL, Shute PW (2005) Reintroduction of four imperiled fishes in Abrams Creek, Tennessee. Southeast Nat 4: 93-110.

16. Lyon JP, Todd C, Nicol SJ, MacDonald A, Stoessel D, et al. (2012) Reintroduction success of threatened Australian trout cod (Maccullochella macquariensis) based on growth and reproduction. Mar Freshwater Res 63 : 598-605.

17. Echelle AF, Echelle AA, Bonnel LK, Allan NL, Brooks JE, et al. (2004) Effects of a restoration effort on an endangered pupfish (Cyprinodon bovinus) after genetic introgression by a non-native species. In: Lozano-Vilano ML, ContrerasBalderas AJ (eds) Homenaje al Doctor Andrés Reséndez Medina. Monterrey, Mexico: Universidad Autónoma de Neuvo León, pp. 129-139.

18. Gumm JM, Snekser JL, Itzkowitz M (2008) Conservation and conflict between endangered desert fishes. Biol Lett 4: 655-658.

19. Kennedy SE (1977) Life history of the Leon Springs Pupfish, Cyprinodon bovinus. Copeia 1977: 93-103.

20. Paciorek T, Al-Shaer L, Itzkowitz M (2014) How territoriality affects the density of an egg predator: habitat renovation and reintroduction as a method of conserving two endangered desert spring fish. Curr Zool 60: 527-533.

21. Black AN, Snekser JL, Al-Shaer L, Paciorek T, Bloch A, et al. (2015). A review of the Leon Springs pupfish (Cyprinodon bovinus) long-term conservation strategy and response to habitat restoration. Aq Conserv.

22. Itzkowitz M (2010) The Leon Springs pupfish recovery project at Diamond $Y$ Draw:further monitoring of the population and the breeding habitat. Texas Parks and Wildlife Department. Final Report Section 6 Grant E-106-1.

23. Bennett VA, Doerr VAJ, Doerr ED, Manning AD, Lindenmayer DB, et al. (2013) Habitat Selection and Behaviour of a Reintroduced Passerine: Linking Experimental Restoration, Behaviour and Habitat Ecology. PLOS One 8 : e54539.

24. Itzkowitz M (1978) Female mate choice in the pupfish, Cyprinodon variegatus Behav Process 3: 1-8.

25. Kodric-Brown A (1983) Determinants of male reproductive success in pupfish (Cyprinodon pecosensis). Anim Behav 31: 128-137.

26. Kodric-Brown A (1977) Reproductive success and the evolution of breeding territories in pupfish (Cyprinodon). Evolution 31: 750-766.

27. Kodric-Brown A (1986) Satellites and sneakers: opportunistic male breeding tactics in pupfish (Cyprinodon pecosensis). Behav Ecol Sociobiol 19: 425-432.

28. Leiser JK, Itzkowitz M (2003) The costs and benefits of territorial neighbors in a Texas pupfish (Cyprinodon bovinus). Behaviour 140: 97-112.

29. Leiser JK, Itzkowitz M (2004) Changing tactics: dominance, territoriality, and the responses of "primary" males to competition from conditional breeders in the variegated pupfish (Cyprinodon variegatus). Behav Process 66: 119-130.

30. Echelle AA, Miller RR (1974) Rediscovery and redescription of the Leon Springs pupfish, Cyprinodon bovinus, from Pecos County, Texas. Southwest Nat 19: 179-190. 
Citation: Al-Shaer L, Bloch A, Paciorek T, Carroll Z, Black A, et al. (2016) Renovated Breeding Habitat Use in Wild \& Captive-bred Populations of an Endangered Desert Pupfish. J Biodivers Endanger Species 4: 156. doi:10.4172/2332-2543.1000156

Page 9 of 9

31. Leiser JK, Itzkowitz M (2003) The breeding system of an endangered pupfish (Cyprinodon elegans). West N Am Naturalist 63: 118-121.

32. Veni G (1991) Delineation and preliminary hydrogeologic investigation of the Diamond Y Spring, Pecos County, Texas. Report to the Texas Chapter of the Nature Conservancy, San Antonio, Texas.

33. Kaufman DW, Peterson SK, Fristik R, Kaufman GA (1983) Effect of microhabitat features on habitat use by Peromyscus leucopus. Is Midl Nat 110: 177-185.

34. Aranha JMR, Takeuti DF, Yoshimura TM (1998) Habitat use and food partitioning of the fishes. Rev Biol Trop 46: 951-959.

35. Mouton AM, Buysse D, Stevens M, Neucker TVD, Coeck J (2011) Evaluation of riparian habitat restoration in a lowland river. River Res Appl 28: 845-857.

36. Werry JM, Lee SY, Lemckert CJ, Otway NM (2012) Natural or Artificial? Habitat-Use by the Bull Shark, Carcharhinus leucas.

37. Chalfoun AD, Martin TE (2007) Assessments of habitat preferences and quality depend on spatial scale and metrics of fitness. J Appl Ecol 44: 983-99.

38. MacArthur R, Pianka E (1966) On optimal use of a patchy environment. Am Nat 100: 603-609.

39. Bar-David S, Bar-David I, Cross PC, Ryan SJ, Knechtel CU, et al. (2009) Methods for assessing movement path recursion with application to African buffalo in south Africa Ecology 90: 2467-2479.

40. Stamps JA, Rishnan VVK, Reid ML (2005) Search costs and habitat selection by dispersers. Ecology 86: 510-518.

41. Qian PY, Pechenik JA (1998) Effects of larval starvation and delayed metamorphosis on juvenile survival and growth of the tube-dwelling polychaete Hydroides elegans. J Exp Mar Bio Ecol 227: 169-185.

42. Danchin E, Cam E (2002) Can non-breeding be a cost of breeding dispersal? Behav Ecol Sociobiol 51: 153-163.

43. Marable MK, Belant JL, Godwin D, Wang G (2012) Effects of resource dispersion and site familiarity on movements of translocated wild turkeys on fragmented landscapes. Behav Process 91: 119-124.

44. Eliassen S, Jorgensen C, Mangel M, Giske J (2007) Exploration or exploitation:
Life expectancy changes the value of learning in foraging strategies. Oikos 116: 513-523

45. Berger-Tal O, Nathan J, Meron E, Saltz D (2014) The exploration-exploitation dilemma: A multidisciplinary framework.

46. Berger-Tal O, Saltz D (2014) Using the movement patterns of reintroduced animals to improve reintroduction success. Curr Zool 60: 515-526.

47. Bertolero A, Oro D, Besnard A (2007) Assessing the efficacy of reintroduction programs by modeling adult survival: the example of Hermann's tortoise. Anim Conserv 10: 360-368.

48. Stamps JA (1988) Conspecific attraction and aggregation in territorial species. Am Nat 131: 329-347.

49. Stamps JA, Swaisgood RR (2007) Someplace like home: experience, habitat selection and conservation biology. Appl Anim Behav Sci 102: 392-409.

50. Pinter-Wollman N, Isbell LA, Hart LA (2009) The relationship between socia behaviour and habitat familiarity in African elephants (Loxodonta africana). Proc R Soc B 276: 1009-1014.

51. Baugh T, Deacon JE (1983) The most endangered pupfish. Freshwater and Marine Aquarium June 1983.

52. Rantanen EM, Buner F, Riordan P, Sotherton N, Macdonald DW (2010) Habitat preferences and survival in wildlife reintroductions: an ecological trap in reintroduced grey partridges. J Appl Ecol 47: 1357-1364

53. Barlow GW (1961) Social Behavior of the Desert Pupfish, Cyprinodon macularius, in the Field and in the Aquarium. Am Mid Nat 65: 339-359.

54. Kodric-Brown A (1978) Establishment and defence of breeding territories in a pupfish (Cyprinodontidae: Cyprinodon). Anim Behav 26: 818-834

55. Echelle, AA (1973) Behavior of the Pupfish, Cyprinodon rubrofluviatilis. Copeia 1: $68-76$.

56. Stoinski TS, Beck BB, Bloomsmith MA, Maple TL (2003) A behaviora comparison of captive-born, reintroduced golden lion tamarins and their wildborn offspring. Behaviour 140: 137-160

57. Armstrong DP, Seddon PJ (2008) Directions in reintroduction biology. Trends Ecol Evol 23: 20-25. 